\title{
Misuses of Computers by Adolescents
}

Henry A. Doenlen, M.D.

Thomas Jefferson University Hospital

Follow this and additional works at: https://jdc.jefferson.edu/jeffjpsychiatry

Part of the Psychiatry Commons

Let us know how access to this document benefits you

\section{Recommended Citation}

Doenlen, M.D., Henry A. (1984) "Misuses of Computers by Adolescents," Jefferson Journal of Psychiatry. Vol. 2 : Iss. 1 , Article 10.

DOI: https://doi.org/10.29046/JJP.002.1.006

Available at: https://jdc.jefferson.edu/jeffjpsychiatry/vol2/iss1/10

This Article is brought to you for free and open access by the Jefferson Digital Commons. The Jefferson Digital Commons is a service of Thomas Jefferson University's Center for Teaching and Learning (CTL). The Commons is a showcase for Jefferson books and journals, peer-reviewed scholarly publications, unique historical collections from the University archives, and teaching tools. The Jefferson Digital Commons allows researchers and interested readers anywhere in the world to learn about and keep up to date with Jefferson scholarship. This article has been accepted for inclusion in Jefferson Journal of Psychiatry by an authorized administrator of the Jefferson Digital Commons. For more information, please contact: JeffersonDigitalCommons@jefferson.edu. 


\title{
MISUSES OF COMPUTERS BY ADOLESCENTS
}

\author{
HENRY A. DOENLEN, M.D.
}

One subject that has been a topic of much recent publicity and concern has been that of computer misuse. Teenage computer programmers gaining entry into the systems of universities, hospitals and businesses have caused the most concern. The duplication of copyrighted programs and information has also been reported to cause loss of considerable money. There seems to be a subpopulation of people who spend considerable time working with computers. These individuals may do so to the exclusion of other aspects of life such as human interaction. This paper will present both my observations of this behavior and my speculations about the motivations behind this behavior.

Before one can understand some of the pathological behaviors associated with the misuse of computers, one should be aware of the mental processes necessary to effectively use computers. A child who can type words can learn to play computer games and write limited programs. However, programs use variables to represent changing numerical and alphabetical values. Thus, a child must understand algebra in order to use a computer with sophistication. The usual age for this understanding to be acquired and for children to become particularly interested in computers is thirteen or fourteen. In the decade that follows, the adolescent normally experiences considerable emotional upset as he attempts to resolve his childhood conflicts. This upset may be expressed by various misuses of computers.

The recent movie War Games exemplifies both the fears and fantasies about unauthorized access to computer data and programs. Shortly after the release of this movie in May, 1983, there was much publicity about a group of male adolescents breaking into the Sloan-Kettering Hospital system as well as sixty other government and business computers systems (1). Ten years ago, people who spent much time using computers were called computer junkies reflecting the addictive nature of the activity. However, such persons are now called hackers. The origins of this term are not known, but considering that the definition of hack is "to cut with irregular or heavy blows or in a random manner" (2), it seems to indicate a destructive tendency.

There are several components to this phenomenon that may relate to unconscious thoughts. The adolescent first learns or discovers the correct passwords that allow him to use his small home computer to visually display the often secret or confidential data in a much larger and more powerful computer. This desire to see inside the equipment of others is reminiscent of similar desires in the four or five year old child who often attempts to see the genitalia of others and tries to enter the room of the parents to discover the primal scene. However, the entry into and study of the larger computer is

Dr. Doenlen is a first-year fellow in the Division of Child Psychiatry. 
not what concerns the owners of large systems. The main problem is the loss or manipulation of data contained in the computer. In order to accomplish this, the hacker must first understand the operating system of the larger computer, which consists of a series of programs that are necessary for the computer to communicate with the computer users and to store and process data in an orderly fashion. On many systems, one can obtain elementary instructions by typing help, but in order to gain access to data which is protected from unauthorized programmers, one must gain a more sophisticated knowledge of the operating system. The adolescent may gain this knowledge through unauthorized access in order to transfer a copy of the operating system by telephone into his own home computer. This activity may relate to the primitive mental mechanism of incorporation, or taking in and digesting the power of a more potent object.

The use of incorporation implies the destruction of the object that was incorporated. The knowledge gained by the hacker gives him the power to alter the memory or processing behavior of the larger computer. He may exercise this power by writing a program that he can insert into the larger computer. In this way, the adolescent puts $a$ little of himself into the larger computer, causing any amount of damage. This may range anywhere from a relatively insignificant transfer of twenty-five cents from one bank account to another, to the loss of medical records at Sloan-Kettering Hospital. One may view the entire sequence of behavior presented thus far as being reminiscent of the oedipal wishes. There is a desire to see something forbidden, and by processes of incorporation and insertion, gain control over the forbidden object. By this behavior the adolescent controls the amount and flow of data retained by the computer. This may reflect an unconscious desire by the programmer to control himself or retaliate against those who have tried to control him in his past.

Related to the activity of breaking into larger computers is the pirating of protected software. The term software refers to programs; hardware refers to physical equipment. Software is protected by writing into the program instructions that prevent the operation of the program by those who did not buy it. Usually this involves the program checking itself to see if it is a copy that was not produced by the manufacturer. The pirate is one who copies for his own use copyrighted programs which he did not buy. This violation of copyrights is known to cost much financial loss to the home computer industry as well as discourage programmers from attempting to make a living from their creations.

There are two different types of pirating behavior, cracking a protected program and then using the program. Some hackers seem to enjoy the challenge of cracking a program which involves the discovery and deactivation of the instructions that protect the program from unauthorized use. This behavior may be psychologically similar to breaking into larger computers. The only difference is that the adolescent is defeating the activity of the much larger software manufacturer instead of an institution that owns a large computer. Generally, those who specialize in cracking the protected software do not spend much time using the program.

In common with both illegal computer entry and software piracy is the desire of the hacker to let others know about his work. Pirated programs are often altered to 
display cracked by ... followed by a pseudonym. The psuedonym is known only to other members of the programmer's club. The clubs may be local such as the 414 club in Milwalkee that was responsible for a number of computer break-ins. They may extend nationally with communication by electronic mail and bulletin boards. By posting messages in electronic bulletin boards, the programmer can obtain narcissistic gratification by exhibiting to others that he has gained control over the larger computers or software manufacturers.

Common to both illegal access and piracy is also the use of services to the advantage of the programmer as in the movie War Games in which adolescents were able to alter their school grades stored in a computer. Others use copyrighted programs and such electronic services as long distance telephone calls without payment. Narcissistic and antisocial defenses are used to justify their behavior. Such adolescents may think that since they are intelligent enough to illegally obtain the service or program, they deserve to use it for free. Their lack of money may be used as a justification for their theft. They often believe that the corporations and institutions from which the services or programs are stolen can easily pay for the loss. Such activity may reflect unconscious anger being expressed in a passive-aggressive manner.

Like the automobile, the computer may be a phallic symbol reflected in behavior as well as in dreams. In one dream of my own, I returned home to find my father had obtained a large printer. In reality, my father has no interest in computers, so the meaning of his large printer is readily apparent. Many computer enthusiasts try to improve the capability and power of their computer by adding memory and storage devices, even if they have no particular use for the computer in their personal or business life. One adolescent expanded his small VIC-20 computer by adding far more memory than the computer was intended to contain. This person wanted to do this to see if it could be done and he remained convinced that he had made a great improvement to his machine. Using the model of a computer as a phallic representation, one can speculate that this adolescent may be acting out symbolically unconscious conflicts involving his own sexuality. Supporting this is his lack of dating and several homosexual references in his own programming.

An individual's excessive use of the computer gives the activity the characteristics of an obsessive-compulsive defense. Since time spent with computers is often time spent not interacting with people, it is apparent that there may be at least an unconscious desire by hackers to avoid, limit, or control their interactions with people. There are groups organized around computer interests, but meetings of such groups are often limited to discussion about the computers or programs. Sometimes a smaller group of programmers will meet to watch each other program. The structuring of time in these groups allows the members to have friends without sharing information of a more personal nature. These groups contain mostly males who often avoid interaction with females. The interactions are usually limited to technical discussions when females are present. Sometimes, computer enthusiasts may talk to each other using their computers and a simulated citizen's band program on a national computer service. The service allows the use of handles to maintain anonymity and the conversations are often superficial. 
Since computers have only recently been in widespread use, the long term effects of computer overuse and misuse are not known. There are stories of young adults becoming quite wealthy because of their knowledge and creativity using computers. Yet it is easy to imagine that many of those who use the computer as an obsessional defense may use it to avoid intimacy and growth with their families and friends. There are already complaints by computer widows similar to those of the football widows. The phenomenon of computer misuse and overuse might be studied through anonymous questionaires given in high schools and colleges where computer users are found. Insight-oriented psychotherapy may be helpful in understanding further the unconscious meaning of this behavior.

\section{REFERENCES}

1. Marbach, WD, Resener, M, Carey, J, et al: Beware: Hackers at Play. Newsweek, September 6: $42-48,1983$

2. Morris, W (ed.): The American Heritage Dictionary of the English Language. New York, American Heritage Publishing Co., 1973 